\title{
Rapid progress towards elimination of lymphatic filariasis in endemic regions of Myanmar as a result of 16 years of anti- filarial activities (2001-2016)
}

\author{
Kyawt Mon Win ${ }^{1 *}$, Jaya Prasad Tripathy ${ }^{2}$, Thae Maung Maung ${ }^{3}$, Tin $\mathrm{Oo}^{3}$, Aung Thi ${ }^{1}$, Khin Nan $\operatorname{Lon}^{4}$ and Zaw Lin ${ }^{1}$
}

\begin{abstract}
Background: As Myanmar progresses towards lymphatic filariasis (LF) elimination, it is important to know how well the anti-filarial activities have performed. The present study was conducted to study the implementation of the key anti-filarial activities and their impact on key indicators of LF transmission.

Methods: A secondary analysis of aggregate program data on the anti-filarial activities was conducted in four endemic state/regions of Myanmar receiving at least six mass drug administration (MDA) rounds during 2001-2016.

Results: MDA coverage has been expanded to cover all the endemic implementation units (IUs), i.e., 45 by 2015 and 6 IUs out of them have already stopped MDA. The reported coverage of MDA ranges from 87 to $100 \%$ whereas surveyed coverage ranges from 78 to $100 \%$ among the eligible population. The prevalence of microfilaria has significantly declined especially in Magway from 4.7 to $0.2 \%$ and Sagaing region from 7.9 to $1.3 \%$ during $2001-2016$. Around $2.5 \%$ of estimated cases of hydrocele were reported to the program during 2009-2014.

Conclusion: Myanmar has achieved significant success in interrupting LF transmission through several MDA rounds with high coverage. However, morbidity reporting and management, being in its initial phase requires an active surveillance system for identifying and managing people with LF-associated morbidities under the program.
\end{abstract}

Keywords: Lymphatic filariasis, Mass drug administration, Myanmar

\section{Background}

Lymphatic filariasis (LF) is a debilitating neglected tropical disease currently infecting around 120 million people in 81 countries. An estimated 1.34 billion live in filarial endemic areas, with $65 \%$ of them residing in World Health Organization (WHO) South-East Asia Region (SEAR). About 40 million people suffer from the stigmatizing and disabling clinical manifestations of the disease, 15 million have lymphoedema (elephantiasis) and 25 million men have urogenital swelling, principally scrotal hydrocele [1].

* Correspondence: kyawtmonwin@gmail.com

${ }^{1}$ Vector Borne Diseases Control Program, Ministry of Health and Sports, Naypyitaw, Myanmar

Full list of author information is available at the end of the article
LF is a major public health problem in the SEAR. Nine out of the 11 countries in the region are endemic for filariasis. In 2000, WHO established the Global Programme to Eliminate Lymphatic Filariasis (GPELF), to achieve LF elimination (LF antigenaemia $<1 / 1000$ population) by 2020. To interrupt transmission, the WHO recommends an annual mass drug administration (MDA) of single doses of two medicines, namely diethylcarbamazine (DEC) or ivermectin plus albendazole to the entire eligible population in endemic areas for at least 5 years [2].

Myanmar is a LF endemic region covering 45/74 districts and 240/330 townships [3]. (Figure 1) Myanmar adopted the WHO guidelines as described above and developed the National Plan to Eliminate Lymphatic Filariasis (NPELF) in 2000 [1, 3].

Analyses of the effect of MDA on transmission of human infection have been documented in countries 


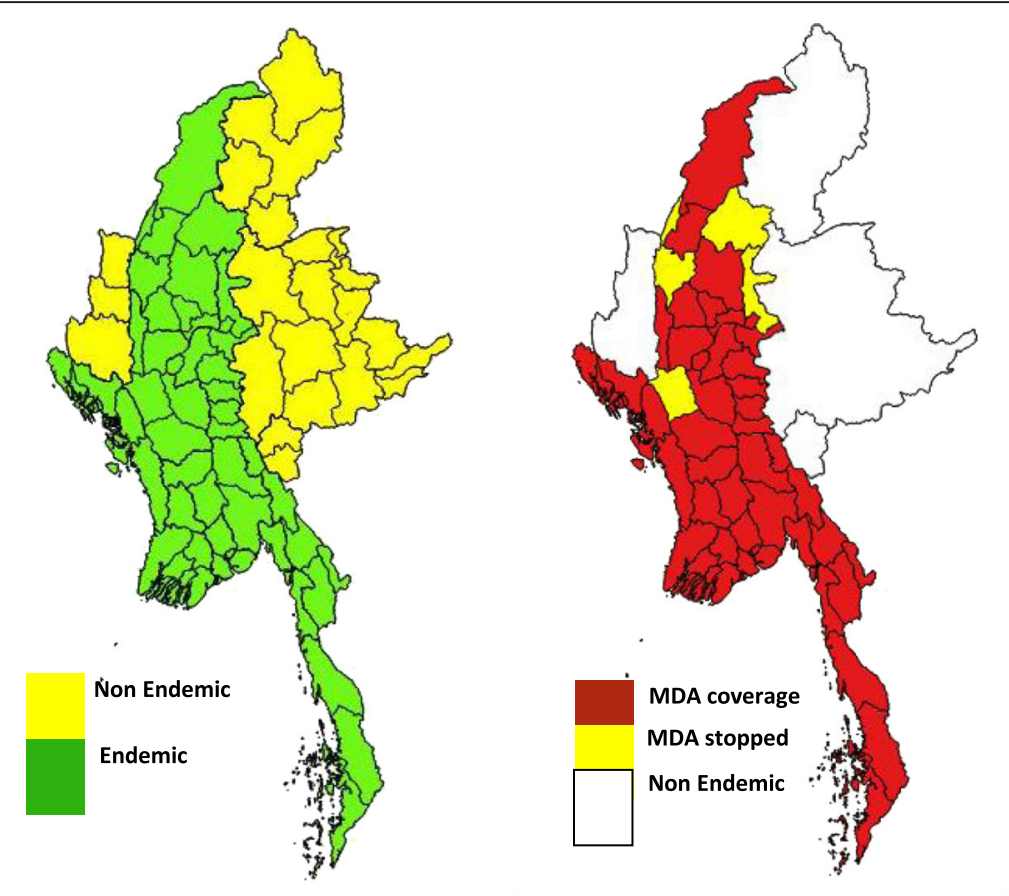

Fig. 1 Map showing lymphatic filariasis-endemic and lymphatic filariasis-non-endemic regions and MDA coverage in Myanmar, 2016. MDA = mass drug administration

such as Egypt [4], Papua New Guinea [5, 6] American Samoa [7, 8], India [9], Sri Lanka [10], Thailand [11], Tanzania [12], and Nigeria [13]. However, there is no published literature on the effect of MDA on the control of filariasis in Myanmar. Among the Southeast Asian countries, Myanmar is considered to be one of the highLF-burden countries. According to a recent review by Dickson et al., there is no scientific evidence from Myanmar on the burden of LF [14]. However, studies have reported high morbidity and LF prevalence along the Thai-Myanmar border and among the migrants from Myanmar in Thailand [15-17].

Myanmar has initiated MDA since 2001 and has expanded to cover the whole of the endemic region in the country with reportedly high coverage rates. This provides us the opportunity to study the effect of MDA on microfilarial transmission in the community under routine program settings. Success in eliminating filaria in Myanmar will require knowledge on how well the anti-filarial activities have succeeded so far.

Thus, the present study was conducted with the following specific objectives: (i) reporting the implementation of key anti-filarial activities (MDA administration and LF-associated morbidity case reporting) and (ii) studying the impact of these activities on key indicators like coverage of MDA, prevalence of microfilaria, and filarial antigenaemia in four filarial endemic state/regions (Magway, Sagaing, Rakhine, and Mandalay) during 2001-2016.

\section{Methods}

\section{Study design}

Aggregate data (ecological design) under the Vector Borne Disease Control (VBDC) Program were summarized at region and district/implementation unit (IU) level.

\section{General setting}

Myanmar, situated in Southeast Asia, has an estimated population of around 52 million, of whom $70 \%$ live in rural areas [18]. Myanmar is $676,578 \mathrm{~km}^{2}$ in size with $49 \%$ forest cover. The country is divided administratively into the capital territory (Nay Pyi Taw Council Territory) and seven states and seven regions, and 74 districts with 412 townships/sub townships [18]. The wet climate and the mountainous topography favors LF transmission especially in the border areas. The districts vary in their population size ranging from $0.1-2.0$ million.

\section{Study setting}

Under the LF elimination program in the country, the following activities have been carried out since 2000: area mapping of LF endemicity, MDA in LF endemic areas, evaluation of MDA (through MDA coverage surveys, night blood surveys, and Transmission Assessment Surveys), and morbidity control activities. In 2011, mapping for LF endemicity was completed which found that 45 out of 65 districts/IUs are LF endemic. MDA was started in 10 townships in Magwe region as a pilot project in 2001. Until 2016, MDA has covered all 45 endemic IUs Fig. 2. 

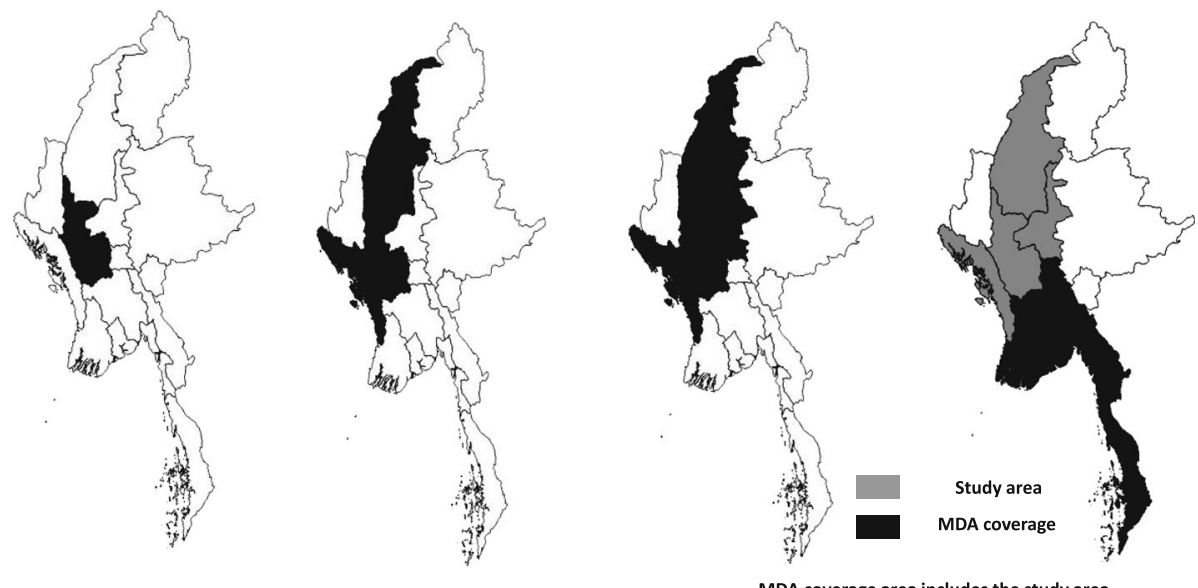

Fig. 2 Map showing geographical expansion of MDA coverage in lymphatic filariasis regions in Myanmar during 2001-2016. MDA = mass drug administration

Four rounds of post-MDA coverage surveys have been carried out to evaluate the reported coverage. Night blood surveys (in spot-check and sentinel sites) and transmission assessment surveys (TAS) were done in accordance with the guidelines. In night blood surveys, finger prick method was used to collect night blood smears in order to identify circulating LF parasite in the blood. Figure 3 shows the chronological order of all anti-filarial activities that have taken place under the LF control program from 2001 to 2015 .

In each sentinel site, a sample was collected from at least 500 individuals aged over 5 years. These sites were chosen randomly from high transmission areas. In each IU/district, one sentinel site was selected. Once chosen,

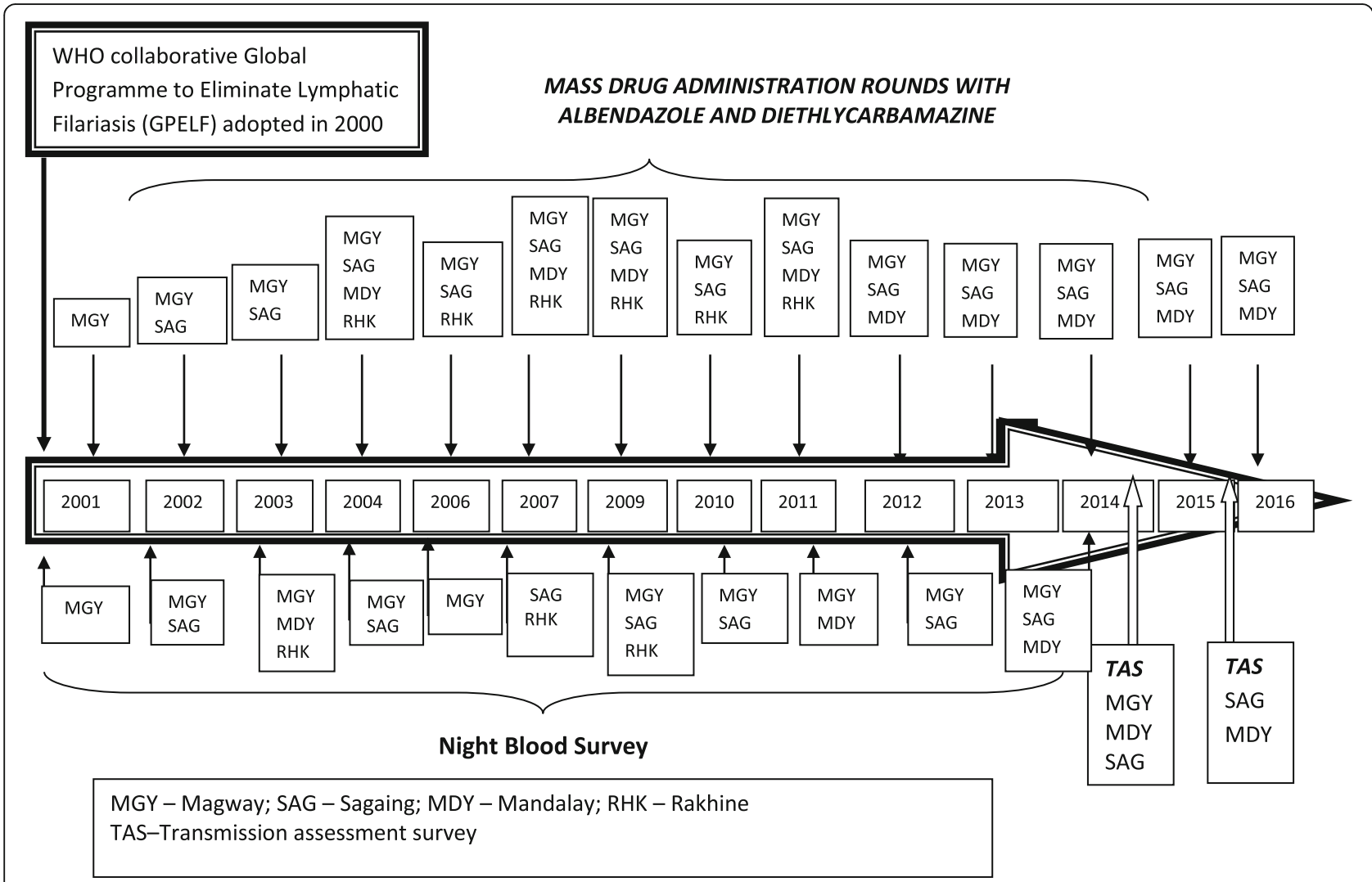

Fig. 3 Chronological order of anti-filarial activities in four endemic regions under the Vector Borne Control Program, Myanmar, 2001-2016 
the same site remained as the sentinel site throughout the course of the program. However, different spotcheck sites were chosen randomly for every assessment. At least one spot-check site was chosen per sentinel site.

MDA was started in 02 IUs of Magway region in 2001, later expanded to $04 \mathrm{IUs}$ in 2002, and 14 rounds have been completed as of 2016. In Sagaing, MDA started in 06 IUs in 2002, and 13 rounds have been completed by 2016. Subsequently, MDA was stopped in 03 IUs in 2009. In Rakhine, MDA was initiated in 2004 in 04 IUs, which was subsequently stopped after having conducted 06 rounds. Similarly, in Mandalay, MDA started in 07 IUs in 2004; 09 rounds have been completed so far Table 1.

\section{Study population}

The study population comprised of the general population in four endemic state and regions of Myanmar (Magway, Sagaing, Mandalay, and Rakhine) where at least six rounds of MDA have been conducted during 2001-2016.

\section{Study duration}

Data compilation, cleaning, and verification were conducted between October 2016 and March 2017, using National VBDC Program data collected from the years 2001 to 2016. Data analysis and manuscript writing was done between April and June 2017.

\section{Data collection and variables}

Aggregate data were collected from the Annual reports of VBDC Program, electronically maintained routine filariasis control program data and reports of surveys such as night blood survey, post-MDA coverage survey and transmission assessment survey during the period 2001-2016. These activities were done as part of the routine activities conducted to monitor and evaluate the anti-filarial control program. All these activities were done according to the standard WHO guidelines [1]. Operational definitions of key terms have been given in Annexure 1. The program data pertaining to LF morbidities (cases of hydrocele) were obtained from hospitals in the public sector. As the National Vector Borne Program staffs including the program manager were part of this study, any discrepancy in the data was cross checked with the respective region/state/township program staff.

\section{Analysis and statistics}

Proportions were used to summarize key indicators such as reported and surveyed coverage of MDA, mf prevalence, and prevalence of filarial antigenaemia. Trends were presented in the form of a line diagram. Mf prevalence in sentinel and spot-check sites was classified into two categories based on a cut-off: $\langle 1 \%$ and $>=1 \%$. Subsequently, number of sites in each category was counted in each night blood survey and has been presented in a tabular form. Data validation was done by checking with the program staff at different levels. Maps were constructed using QGIS software (version 2.18.3) to denote the filarial endemic regions and the expansion of MDA coverage in the country. Estimated cases of hydrocele were calculated by taking prevalence of hydrocele as $5.9 \%$ among adults > 15 years of age from a community-based survey carried out in Mandalay region in 2014 (unpublished data). This was then projected onto the adult population ( $>15$ years) of the respective state/region. These estimated figures were then compared with the reported cases under the National VBDC Program.

\section{Ethics approval and consent to participate}

Ethics approval for this study was obtained from The Union Ethics Advisory Group (International Union against Tuberculosis and Lung Disease, Paris, France) (EAG Number: 79/16) and the Institutional Ethics Review Committee, Department of Medical Research, Myanmar (Ethics/DMR/ 20117/018).

\section{Results \\ Coverage of MDA rounds}

MDA rounds started in 2 IUs of Magway in 2001 covering 1.8 million population expanding to 33 million in 2016. A total of 14 rounds of MDA have been conducted in Magway region, 13 rounds in Sagaing, and nine rounds in Mandalay whereas six rounds of MDA were carried out in Rakhine state within the period of 2001-

Table 1 Details of MDA coverage and compliance rates by in four endemic regions/states of Myanmar

\begin{tabular}{llllll}
\hline Region/state & No. of endemic IUs & No. of MDA rounds & Period of MDA coverage & Reported coverage in \% (range) & Compliance rate in \% (range) \\
\hline Magway & $04^{\mathrm{a}}$ & 14 & $2001-2016$ & $95(89-99)$ & $94(90-100)$ \\
Sagaing & $06^{\mathrm{b}}$ & 13 & $2002-2016$ & $94(87-100)$ & $92(78-100)$ \\
Mandalay & 07 & 09 & $2004-2016$ & $94(89-97)$ & $94(93-95)$ \\
Rakhine & $04^{c}$ & 06 & $2004-2011$ & $96(91-99)$ & $96(95-97)$ \\
\hline
\end{tabular}

IU implementation unit, MDA mass drug administration

${ }^{a}$ MDA started in 02 IUs in 2001, later 02 more IUs were added in 2002

${ }^{b}$ MDA started in 06 IUs, later stopped in 03 IUs in 2009

${ }^{c}$ MDA started in 04 IUs, later stopped in all 04 IUs in 2009 


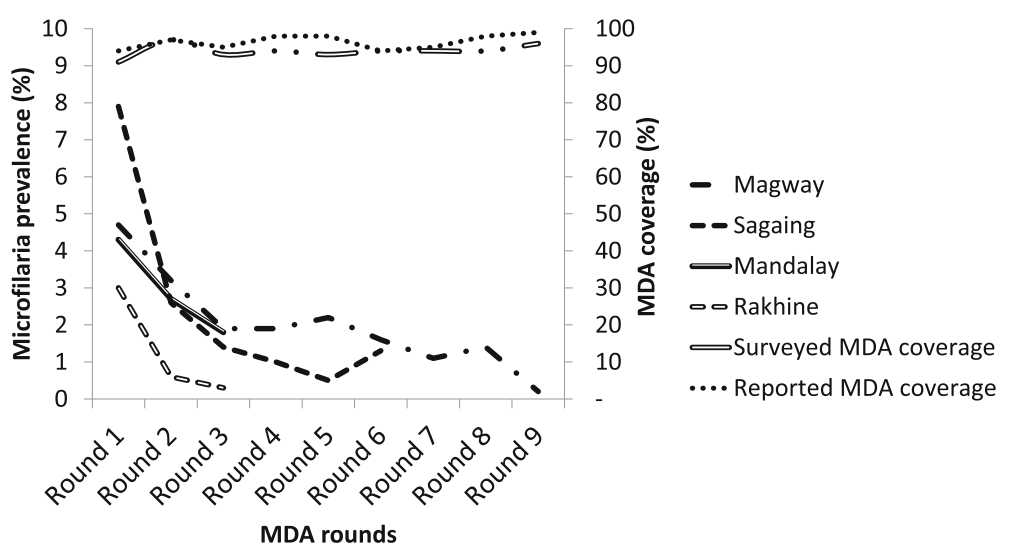

Fig. 4 Trend in the prevalence of microfilaria and the overall MDA coverage after multiple MDA rounds in four endemic state/regions of Myanmar during 2001-2015. MDA = mass drug administration

Table 2 Impact of MDA on microfilaria prevalence at sentinel sites in four endemic regions/states of Myanmar

\begin{tabular}{|c|c|c|c|c|c|c|c|}
\hline \multirow{3}{*}{$\begin{array}{l}\text { Region/state } \\
\text { Magway }\end{array}$} & \multirow{3}{*}{$\begin{array}{l}\text { No. of endemic } \\
\text { IUs }{ }^{\mathrm{a}} \\
04\end{array}$} & \multirow{3}{*}{$\begin{array}{l}\text { Year of post-MDA } \\
\text { survey } \\
2001\end{array}$} & \multirow{3}{*}{$\begin{array}{l}\text { No. of sentinel } \\
\text { sites } \\
04\end{array}$} & \multirow{3}{*}{$\begin{array}{l}\text { mf prevalence } \\
\text { (range) }\end{array}$} & \multirow{3}{*}{$\begin{array}{l}\text { Overall mf prevalence } \\
(\%)\end{array}$} & \multicolumn{2}{|c|}{$\begin{array}{l}\text { No. of sentinel } \\
\text { sites with mf } \\
\text { prevalence } \\
\end{array}$} \\
\hline & & & & & & & \\
\hline & & & & & & 0 & 4 \\
\hline & & 2002 & 04 & $0.19-9.17$ & 3.9 & 1 & 3 \\
\hline & & 2003 & 04 & $0.19-4.0$ & 2.6 & 1 & 3 \\
\hline & & 2004 & 04 & $0.0-2.5$ & 1.45 & 1 & 3 \\
\hline & & 2005 & 04 & $0.4-3.4$ & 1.8 & 1 & 3 \\
\hline & & 2007 & 04 & $0.0-2.5$ & 1.1 & 2 & 2 \\
\hline & & 2008 & 04 & $0.0-2.8$ & 1.12 & 3 & 1 \\
\hline & & 2010 & 04 & $0.0-2.7$ & 1.45 & 2 & 2 \\
\hline & & 2011 & 04 & $0.0-0.4$ & 0.2 & 4 & 0 \\
\hline & & 2012 & 02 & $0.8-2.2$ & 1.5 & 1 & 1 \\
\hline & & 2014 & 01 & 0.33 & 0.33 & 1 & 0 \\
\hline Sagaing & 06 & 2002 & 06 & $3.0-15.1$ & 7.9 & 0 & 6 \\
\hline & & 2004 & 06 & $0.6-4.7$ & 2.6 & 1 & 5 \\
\hline & & 2007 & 06 & $0.0-3.6$ & 1.43 & 2 & 4 \\
\hline & & 2009 & 06 & $0.0-2.1$ & 0.9 & 4 & 2 \\
\hline & & 2010 & 02 & $0.0-1.7$ & 0.8 & 1 & 1 \\
\hline & & 2012 & 01 & 0.79 & 0.79 & 1 & 0 \\
\hline & & 2014 & 05 & $0.0-1.89$ & 1.1 & 3 & 2 \\
\hline Mandalay & 07 & 2003 & 10 & $0.2-14.7$ & 5.0 & 3 & 7 \\
\hline & & 2011 & 13 & $0.0-8.8$ & 2.7 & 5 & 8 \\
\hline & & 2014 & 12 & $0.0-3.2$ & 1.19 & 6 & 6 \\
\hline Rakhine & 04 & 2003 & 06 & $0.0-12.6$ & 3.0 & 2 & 4 \\
\hline & & 2007 & 08 & $0.0-2.8$ & 0.57 & 6 & 2 \\
\hline & & 2009 & 07 & $0.0-0.8$ & 0.26 & 7 & 0 \\
\hline
\end{tabular}


2016. Table 1 shows the details of the number of endemic IUs, number of MDA rounds, and coverage of MDA in four study regions/states. MDA coverage has been expanded to cover all the endemic IUs (45) by 2015, and 6 IUs out of them have already stopped MDA in the study area Figs 1 and 2.

\section{Trend in prevalence of microfilaremia and MDA coverage} The reported coverage of MDA rounds ranges from 87 to $100 \%$ for the eligible population whereas surveyed coverage ranges from 78 to $100 \%$ among the eligible population. The prevalence of microfilaria in Magway was $4.7 \%$ in 2001 , which reduced to one-third (1.6\%) in 2007 and further dipped to $0.2 \%$ in 2014. In Sagaing region, microfilaremia dipped from $7.9 \%$ in 2002 to $1.3 \%$ in 2014. Similarly, the Mandalay region and Rakhine state also witnessed a sharp decline in microfilaremia rates Fig. 4.

\section{Effect of MDA on mf prevalence in sentinel and spot-check sites}

Tables 2 and 3 show the mf prevalence in sentinel and spot-check sites in several night blood surveys conducted during the study period in the four regions/ states. It shows that the number of sentinel and spotcheck sites with $\mathrm{mf}$ prevalence $>=1 \%$ have come down during this period. Table 4 shows the sentinel-wise trend in the prevalence of microfilaria. It suggests that although $\mathrm{mf}$ prevalence has come down significantly in many sites, some pockets in districts like Pakokku (Magway), Shwebo (Sagaing), Myingyan, Mandalay, Meikhtila, and Kyauk Se (Mandalay) have persistently high levels of $\mathrm{mf}$ prevalence. Table 5 shows the overall impact of MDA on $\mathrm{mf}$ prevalence in sentinel sites IU wise in four states/regions of Myanmar.

\section{Reporting of hydrocele cases}

Figure 5 shows the estimated cases versus reported cases of hydrocele in four endemic state and regions of Myanmar during 2009-2014. Around 2.5\% of estimated cases of hydrocele were reported to the program.

\section{Results of transmission assessment surveys}

TAS has been conducted in 07 out of 21 IUs in the four endemic state/regions. Overall, 14,476 children were tested for LF antigen in TAS and $36(0.25 \%)$ had test positive. TAS in three state/regions (6 out of 07 IUs) showed very low proportion $(<1 \%)$ of LF antigenaemia

Table 3 Impact of MDA on microfilaria prevalence at spot-check sites in four endemic regions/states of Myanmar

\begin{tabular}{|c|c|c|c|c|c|c|c|}
\hline Region/state & No of endemic IUs & $\begin{array}{l}\text { Year of post-MDA } \\
\text { survey }\end{array}$ & $\begin{array}{l}\text { No. of spot-check } \\
\text { sites }\end{array}$ & $\begin{array}{l}\text { mf prevalence } \\
\text { (range) }\end{array}$ & $\begin{array}{l}\text { Overall mf prevalence } \\
(\%)\end{array}$ & $\begin{array}{l}\text { No. of } \\
<1 \%\end{array}$ & $\begin{array}{l}s \text { with } \mathrm{mf} \\
>=1 \%\end{array}$ \\
\hline \multirow[t]{8}{*}{ Magway } & \multirow[t]{8}{*}{04} & 2003 & 05 & $0.0-7.6$ & 2.2 & 3 & 2 \\
\hline & & 2004 & 04 & $0.6-2.8$ & 1.7 & 1 & 3 \\
\hline & & 2005 & 04 & $3.0-7.2$ & 5.1 & 0 & 4 \\
\hline & & 2006 & 04 & $0.2-1.4$ & 0.6 & 3 & 1 \\
\hline & & 2008 & 04 & $1.9-2.5$ & 1.3 & 0 & 4 \\
\hline & & 2009 & 02 & $0.0-0.8$ & 0.4 & 2 & 0 \\
\hline & & 2012 & 07 & $0.0-6.6$ & 1.2 & 4 & 3 \\
\hline & & 2014 & 01 & 0.6 & 0.6 & 1 & 0 \\
\hline \multirow[t]{5}{*}{ Sagaing } & \multirow[t]{5}{*}{06} & 2004 & 06 & $0.0-6.6$ & 2.6 & 4 & 2 \\
\hline & & 2007 & 06 & $0.0-5.6$ & 2.7 & 1 & 5 \\
\hline & & 2008 & 04 & $0.2-5.6$ & 2.0 & 2 & 2 \\
\hline & & 2009 & 06 & $0.0-5.6$ & 1.5 & 4 & 2 \\
\hline & & 2014 & 05 & $0.0-0.0$ & 0.0 & 5 & 0 \\
\hline \multirow[t]{2}{*}{ Mandalay } & \multirow[t]{2}{*}{07} & 2011 & 04 & $0.0-3.8$ & 1.5 & 2 & 2 \\
\hline & & 2014 & 01 & 0.0 & 0.0 & 1 & 0 \\
\hline \multirow[t]{3}{*}{ Rakhine } & \multirow[t]{3}{*}{04} & 2008 & 04 & $0.0-0.6$ & 0.3 & 4 & 0 \\
\hline & & 2010 & 04 & $0.0-0.6$ & 0.2 & 4 & 0 \\
\hline & & 2015 & 02 & 0.0 & 0.0 & 2 & 0 \\
\hline
\end{tabular}

IU implementation unit, MDA Mass Drug Administration, $\mathrm{mf}$ microfilaria 
Table 4 Trend in the prevalence of microfilaria at different sentinel sites in four endemic region/states of Myanmar during the period 2001-2016

\begin{tabular}{|c|c|c|c|c|c|c|c|c|c|c|c|c|c|c|c|c|}
\hline District & Township & Sentinel site & 2001 & 2002 & 2003 & 2004 & 2005 & 2006 & 2007 & 2008 & 2009 & 2010 & 2011 & 2012 & 2013 & 2014 \\
\hline \multicolumn{17}{|l|}{ Magway } \\
\hline \multirow[t]{2}{*}{ Magway } & Chauk & No 1 ward & 7.1 & & 3.6 & & 1.7 & & & 2.8 & 1.0 & & 0.4 & & & \\
\hline & Myothit & Myolulin & 1.1 & & 0.2 & & 0.4 & & & 0.0 & & & 0.0 & & & \\
\hline \multirow[t]{2}{*}{ Thayet } & Thayet & PyiTawAye & 6.3 & & 2.4 & & 3.4 & & & 0.8 & & & 0.4 & & & \\
\hline & Kanma & Pahtoe & & 3.0 & & 1.2 & & & 0.0 & 0.9 & & & 0.0 & & & \\
\hline \multirow[t]{2}{*}{ Pakokku } & Pakokku & Kamma & & 0.2 & & 0.0 & & & 0.0 & & & 0.0 & & & & \\
\hline & Yesagyo & No. 8 & & 9.2 & & 2.5 & & & 2.5 & & & 2.7 & & 2.2 & & \\
\hline \multirow[t]{2}{*}{ Minbu } & Salin & Sinphyukyun & & 3.3 & & 2.1 & & & 1.8 & & & 2.7 & & 0.8 & & \\
\hline & Minbu & KyaukTan & 4.4 & & 4.0 & & 1.8 & & & & & 0.4 & & & & 0.3 \\
\hline \multicolumn{17}{|l|}{ Sagaing } \\
\hline \multirow[t]{2}{*}{ Sagaing } & Sagaing & Ayemyawaddy & & 7.0 & & 3.0 & & & 3.6 & & 0.9 & & & & & \\
\hline & Sagaing & Nyaungpinwynn & & 3.0 & & 1.0 & & & 0.6 & & 0.2 & & & & & \\
\hline \multirow[t]{2}{*}{ Monywa } & Tabayin & Aye tharyar & & 5.5 & & 2.2 & & & 1.6 & & 0.4 & & & & & \\
\hline & Budalin & Minywa & & 5.2 & & 0.6 & & & 0.0 & & 0.0 & & & & & \\
\hline \multirow[t]{2}{*}{ Shwebo } & Taze & PawOo, BoMya & & 15.1 & & 4.7 & & & 1.2 & & 2.1 & 1.7 & & 0.8 & & 1.9 \\
\hline & Depeyin & Saipyin & & 11.5 & & 3.9 & & & 1.6 & & 1.8 & 0.0 & & & & 1.3 \\
\hline \multicolumn{17}{|l|}{ Mandalay } \\
\hline \multirow[t]{2}{*}{ Nyaung $U$} & Nyaung $U$ & Tharyarwady & & & & & & & & & & & 0.4 & & & 1.3 \\
\hline & Nyaung $U$ & Taung Ba & & & & & & & & & & & 0 & & & \\
\hline \multirow[t]{2}{*}{ Yamethin } & Leway & Naung Bo & & & 3.0 & & & & & & & & 2.5 & & & 0.5 \\
\hline & Tatkone & Sayasan ward & & & 6.0 & & & & & & & & 5.2 & & & 0.2 \\
\hline \multirow[t]{2}{*}{ Meikhtila } & Thazi & Nyaungyan & & & 1.7 & & & & & & & & 0.2 & & & 0.2 \\
\hline & Wandwin & Myopaw Ward & & & 7.2 & & & & & & & & 4.6 & & & 1.9 \\
\hline \multirow[t]{2}{*}{ Mandalay } & Amarapur & Tharlayswa & & & 6.8 & & & & & & & & 8.8 & & & 1.7 \\
\hline & Maha aung myay & Thanhletmaw west & & & 0.7 & & & & & & & & 0.6 & & & 0.2 \\
\hline \multirow[t]{2}{*}{ Kyauk Se } & Tada Oo & Thargaung & & & & & & & & & & & 3.7 & & & 2.1 \\
\hline & Myitha & Ahshe/Taung ywa & & & & & & & & & & & 1.5 & & & \\
\hline \multirow[t]{2}{*}{ Myingyan } & Kyaukpadaung & Daungle & & & 13.3 & & & & & & & & 4.6 & & & 3.2 \\
\hline & Nahtogyi & Tanzin & & & 3.4 & & & & & & & & 2.7 & & & 1.3 \\
\hline \multirow[t]{2}{*}{ Pyin Oo Lwin } & Madaya & Latkaunglay & & & 0.2 & & & & & & & & 0.0 & & & \\
\hline & Pyin Oo Lwin & Myopaw ward & & & 0.4 & & & & & & & & & & & 0.3 \\
\hline \multicolumn{17}{|l|}{ Rakhine } \\
\hline \multirow[t]{2}{*}{ Sittwe } & Sittwe & Kathe & & & 12.6 & & & & 2.8 & & 0.8 & & & & & \\
\hline & Sittwe & Shanywa & & & 1.4 & & & & 0 & & 0 & & & & & \\
\hline \multirow[t]{2}{*}{ Maungdaw } & Maungdaw & Kyainchaung & & & 0.16 & & & & 0 & & 0 & & & & & \\
\hline & Maungdaw & No.1 ward & & & 1.7 & & & & 0 & & 0 & & & & & \\
\hline Kyaukphyu & Pauktaw & Paikseik & & & 2.34 & & & & 1 & & 0.2 & & & & & \\
\hline & Kyaukphyu & T.b.chaung & & & & & & & 0.8 & & 0.8 & & & & & \\
\hline Thandwe & Thandwe & Kinmaw & & & 0 & & & & 0 & & 0 & & & & & \\
\hline & Thandwe & No.1 ward & & & & & & & 0 & & & & & & & \\
\hline
\end{tabular}

Figures in the tables are microfilaria prevalence expressed in percentages

leading to stoppage of MDA rounds in those regions. The LF antigenaemia in Shwebo district of Sagaing region was $1.4 \%$ leading to continuation of MDA Table 6.

\section{Discussion}

This is one of the very few studies in Myanmar showing the impact of various anti-filarial activities on key program 
Table 5 Impact of MDA on mf prevalence at the level of the implementation unit in four states/regions of Myanmar during 2001-2016

\begin{tabular}{|c|c|c|c|c|c|c|c|c|c|}
\hline \multirow[t]{2}{*}{ State/region } & \multirow[t]{2}{*}{$\begin{array}{l}\text { Name of } \\
\text { IU }\end{array}$} & \multirow[t]{2}{*}{$\begin{array}{l}\text { Baseline mf } \\
\text { prevalence }\end{array}$} & \multirow[t]{2}{*}{$\begin{array}{l}\text { No of } \\
\text { MDAs }\end{array}$} & \multirow[t]{2}{*}{$\begin{array}{l}\text { MDA compliance rate } \\
\text { (range) }\end{array}$} & \multirow[t]{2}{*}{$\begin{array}{l}\text { Mf prevalence } \\
\text { (range) }\end{array}$} & \multicolumn{2}{|c|}{$\begin{array}{l}\text { No. of sites } \\
\text { with } \mathrm{mf} \text { prevalence }\end{array}$} & \multirow[t]{2}{*}{$\begin{array}{l}\text { Filarial antigen } \\
\text { prevalence }\end{array}$} & \multirow[t]{2}{*}{$\begin{array}{l}\text { Decision about } \\
\text { MDA status }\end{array}$} \\
\hline & & & & & & $<1 \%$ & $>=1$ & & \\
\hline \multirow[t]{4}{*}{ Magway } & Magway & 4.1 & 13 & $92-96$ & $0.0-7.1$ & 5 & 6 & 2.4 & Continue \\
\hline & Thayet & 7.1 & 13 & $93-96$ & $0.0-6.3$ & 5 & 5 & 3.6 & Continue \\
\hline & Pakoku & 9.2 & 13 & $92-96$ & $0.0-9.2$ & 4 & 5 & 3.8 & Continue \\
\hline & Minbu & 4.4 & 12 & $94-97$ & $0.3-4.4$ & 3 & 7 & 3.3 & Continue \\
\hline \multirow[t]{3}{*}{ Sagaing } & Sagaing & 5 & 12 & $93-96$ & $0.2-7$ & 3 & 5 & 4.7 & Continue \\
\hline & Monywa & 5 & 12 & $92-96$ & $0.0-5.5$ & 4 & 4 & 3.8 & Continue \\
\hline & Shwebo & 8 & 12 & $93-95$ & $0.0-15.1$ & 2 & 11 & 6.8 & Continue \\
\hline \multirow[t]{7}{*}{ Mandalay } & Nyaung U & & 8 & $94-97$ & $0.4-1.3$ & 2 & 1 & 0.8 & Continue \\
\hline & Yamethin & 4.5 & 8 & $93-97$ & $0.2-6.0$ & 2 & 4 & 2.4 & Continue \\
\hline & Meikhtila & 4 & 8 & $92-95$ & $0.2-7.2$ & 2 & 4 & 2.6 & Continue \\
\hline & Mandalay & 4.5 & 8 & $91-96$ & $0.2-8.8$ & 3 & 3 & 3 & Continue \\
\hline & Kyauk Se & & 8 & $94-96$ & $1.5-3.7$ & 0 & 3 & 2.4 & Continue \\
\hline & Myingyan & 8 & 8 & $93-97$ & $1.3-13.3$ & 0 & 6 & 3.2 & Continue \\
\hline & Pyin Oo Lwin & 0.3 & 8 & $92-97$ & $0.0-0.4$ & 5 & 0 & 0.5 & Stop \\
\hline \multirow[t]{4}{*}{ Rakhine } & Sittwe & 7 & 6 & $92-96$ & $0.0-12.6$ & 3 & 3 & 1 & Stop \\
\hline & Maungtaw & 1 & 6 & $93-96$ & $0.0-1.6$ & 5 & 1 & 0.8 & Stop \\
\hline & Kyaukphyu & 1 & 6 & $94-97$ & $0.0-2.34$ & 3 & 2 & 1 & Stop \\
\hline & Thandwe & 0 & 6 & $95-96$ & $0-0$ & 4 & 0 & 0 & Stop \\
\hline
\end{tabular}

indicators since the country adopted the WHO GPELF. The two key findings of the study are (a) at least six MDA rounds with high coverage rates in the endemic regions have led to a significant decline in the prevalence of microfilaria and filarial antigenaemia leading to stoppage of MDA in six implementation units, and (b) there is gross underreporting of cases of hydrocele, which is one of the significant morbidities associated with LF.

This evidence from Myanmar adds to the growing body of literature demonstrating that five to six rounds of MDA with high coverage, using DEC+ALB, will reduce $\mathrm{mf}$ prevalence to $<1.0 \%$, hence having significant implications for LF elimination programs $[9,13,19]$.

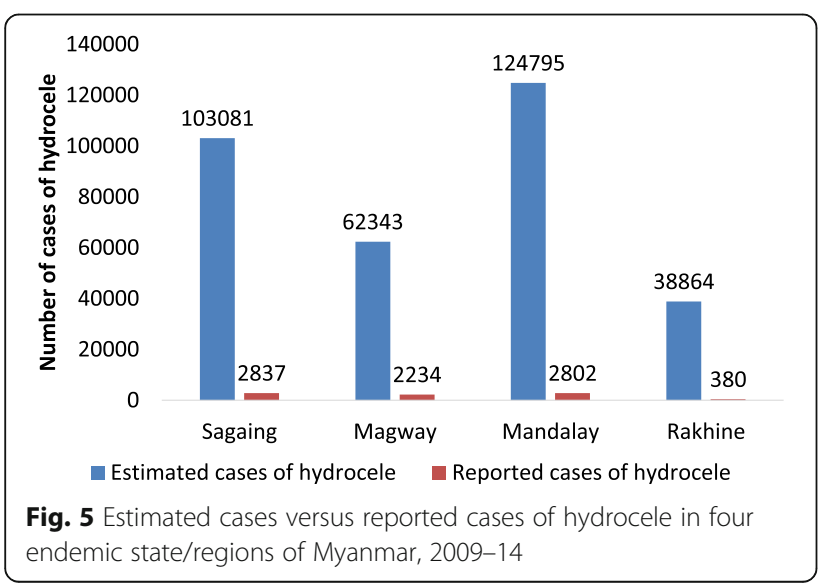

However, this interpretation should be read with caution because the present study reports only MDA coverage, i. e., receipt of drugs whereas GPELF actually recommends a threshold of $65 \%$ compliance, i.e., actual ingestion of tablets for LF elimination. Although there are post-MDA surveys reporting actual MDA coverage, there are no reliable data on the actual compliance to MDA due to lack of clear definitions. This has important implications for setting and reaching elimination targets. A review of 36 MDA studies by Babu et al. in India found compliance to be $22 \%$ lower than MDA coverage [20]. Another review by Shuford et al. in 2016 revealed substantial heterogeneity across terminologies and definitions used to assess compliance [21]. Standardization of the compliance definitions coupled with longitudinal research in systematic non-compliance should be essential elements in the programmatic shift from control to elimination. Compliance surveys following each MDA round should be done under supervision and with the help of trained investigators and using a standard procedure to get more reliable data on actual consumption of drugs. Directly observed swallowing of the tablets during MDA rounds should be emphasized and monitored.

In the four endemic state/regions with more than six MDA rounds, only seven TAS have been conducted out of 21 IUs eligible for TAS. TAS provides the evidence for stoppage of MDA and thus is an important step towards LF elimination. The country should make all 
Table 6 Transmission Assessment Survey in four endemic state/regions of Myanmar, 2008-2015

\begin{tabular}{|c|c|c|c|c|c|c|}
\hline Region & District/IU & TAS & Year & Children $(N)$ & Test positive $N(\%)$ & MDA status \\
\hline \multirow[t]{6}{*}{ Sagaing } & Kalay & Yes & 2008 & 3011 & $0(0.0)$ & Stopped \\
\hline & Tamu & Yes & & 3081 & $0(0.0)$ & Stopped \\
\hline & Kathar & Yes & & 3003 & $0(0.0)$ & Stopped \\
\hline & Shwebo & Yes & 2015 & 2104 & $30(1.4)$ & Continue \\
\hline & Sagaing & No & & & & \\
\hline & Monywa & No & & & & \\
\hline \multirow[t]{4}{*}{ Magway } & Minbu & Yes & 2014 & 1565 & $1(0.06)$ & Stopped \\
\hline & Pakokku & No & & & & \\
\hline & Magway & No & & & & \\
\hline & Thayet & No & & & & \\
\hline \multirow[t]{7}{*}{ Mandalay } & Pyin Oo Lwin & Yes & 2014 & 2500 & $0(0.0)$ & Stopped \\
\hline & Nyaung Oo & Yes & 2015 & 1712 & $5(0.3)$ & Stopped \\
\hline & Kyauksel & No & & & & \\
\hline & Myingyan & No & & & & \\
\hline & Yae Mae Thin & No & & & & \\
\hline & Mandalay & No & & & & \\
\hline & Meikhti Lar & No & & & & \\
\hline \multirow[t]{4}{*}{ Rakhine } & Maungdaw & No & & & & \\
\hline & Mrauk U & No & & & & \\
\hline & Kyauk Pyu & No & & & & \\
\hline & Thandwe & No & & & & \\
\hline Overall & & & & 14,476 & $36(0.25)$ & \\
\hline
\end{tabular}

MDA mass drug administration, NA not applicable, TAS Transmission Assessment Survey, IU implementation unit

efforts to conduct further TAS rounds in accordance with the NPELF. Support from international agencies is required in this endeavor.

Although night blood surveys have shown decrease in the number of sentinel/spot-check sites with $\mathrm{mf}$ prevalence $>=1 \%$, certain pockets (sentinel sites) have shown persistence of microfilaria which requires intensification of the LF activities and regular monitoring. Despite several rounds of MDA, pockets of high microfilaremia might indicate poor compliance to the drugs in terms of actual ingestion of the drugs, which needs further investigation.

Entomological surveillance is another method for monitoring the impact of MDA on LF transmission, apart from serological and parasitological indicators [1]. However, review of anti-filarial activities in the last 16 years in Myanmar showed no such activity. As we progress towards LF elimination, this could be a key indicator in monitoring our progress towards the goal of elimination of LF, thus warranting its inclusion in the VBCD Program strategy $[1,22]$.

Managing morbidity and preventing disability among those already affected by LF is one of the two main pillars of LF elimination. To this end, the GPELF recommends that all endemic countries should be collecting and reporting data on morbidity management, although there is no recommended method for collecting such data [1]. Currently, the focus of VBDC in Myanmar is primarily on interrupting transmission through MDA. The present study reports gross underreporting of hydrocele cases. Moreover, the miniscule number of cases which are reported are in fact hospital-reported ones, and that too from public sector hospitals only. This means that many undiagnosed cases of hydrocele in the community go unreported. Also, there is no data on other morbidities such as lymphedema. There is no mechanism of active community-based case reporting of LF-associated morbidities such as hydrocele and lymphedema. Global efforts in terms of morbidity prevention are yet to gain momentum with only 27 out of 81 endemic countries having active morbidity management programs. It is thus strongly recommended that an active community-based surveillance of cases and a plan to manage people with such morbidities should be put in place under the VBDC Program in Myanmar [23]. Hospital-based reporting of LF morbidities should be strengthened. The program also must focus on managing chronic morbidities, which persists even after transmission has been interrupted. This requires strengthening 
of the health facilities in delivering minimum package of MMDP (Morbidity Management and Disability Prevention) care.

What are the key challenges to LF program implementation in Myanmar? We speculate that decades of political and economic turmoil, unique geography, and migration dynamics have played their part in the continued transmission of the disease. Lack of reliable epidemiological data and a constrained public health system are also retarding efforts to eradicate the disease. Although the WHO recommends annual treatment, there have been gaps of 1-2 years between rounds as a result of financial and logistic issues. Despite these challenges, Myanmar has continued to make significant progress towards LF elimination. However, it requires sustained funding and a robust surveillance system yielding accurate data.

The major strength of the study is that it reported program data from four major LF endemic states/regions during a 16-year period (2001-2016) since Myanmar formulated its NPELF in 2000. This is also the first piece of evidence from Myanmar documenting the impact of several rounds of MDA on LF transmission. We feel that the results of the study could be generalizable to the entire country because of similar program guidelines, demography and other factors affecting LF transmission. However, the aggregate data analyzed in this study were obtained from the routine program records, and there was no means of validating the data which we acknowledge as a limitation in this study.

\section{Conclusion}

In four high-LF endemic regions/states, Myanmar has done well in interrupting LF transmission through several MDA rounds with high coverage, but morbidity reporting and management has not been given due attention. Thus, an active surveillance system for identifying and managing people with LF-associated morbidities should be instituted under the program. The program should also make efforts to get reliable epidemiological data for continuous monitoring and evaluation.

\section{Abbreviations}

DEC: Diethylcarbamazine; GPELF: Global Programme to Eliminate Lymphatic Filariasis; IU: Implementation unit; LF: Lymphatic filariasis; MDA: Mass drug administration; NPELF: National Plan to Eliminate Lymphatic Filariasis; TAS: Transmission Assessment Survey; VBDC: Vector Borne Disease Control; WHO: World Health Organization

\footnotetext{
Acknowledgements

This research was conducted through the Structured Operational Research and Training Initiative (SORT IT), a global partnership led by the Special Programme for Research and Training in Tropical Diseases at the World Health Organization (WHO/TDR). The model is based on a course developed jointly by the International Union Against Tuberculosis and Lung Disease (The Union) and Medécins sans Frontières (MSF/Doctors Without Borders). The specific SORT IT programme which resulted in this publication was jointly organized and implemented by The Centre for Operational Research, The Union, Paris, France; The Department of Medical Research, Ministry of
}

Health and Sports, Myanmar; The Department of Public Health, Ministry of Health and Sports, Myanmar; The Union Country Office, Mandalay, Myanmar; The Union South-East Asia Office, New Delhi, India; the Operational Research Unit (LUXOR), MSF Brussels Operational Center, Luxembourg; and Burnet Institute, Australia.

\section{Funding}

The training program in which this paper was developed was funded by the Department for International Development (DFID), UK. The funders had no role in study design, data collection and analysis, decision to publish, or preparation of the manuscript.

\section{Availability of data and materials}

Routine program data and reports during the period 2001-2016 were analysed in this paper. However, data are available from the corresponding author (KMW) and will be made accessible on request at the following email: kyawtmonwin@gmail.com.

\section{Authors' contributions}

All authors read and approved the final manuscript.

\section{Ethics approval}

Ethics approval for this study was obtained from The Union Ethics Advisory Group (International Union against Tuberculosis and Lung Disease, Paris, France) (EAG Number: 79/16) and the Institutional Ethics Review Committee, Department of Medical Research, Myanmar (Ethics/DMR/20117/018).

\section{Consent for publication}

Not applicable

\section{Competing interests}

The authors declare that they have no competing interests.

\section{Publisher's Note}

Springer Nature remains neutral with regard to jurisdictional claims in published maps and institutional affiliations.

\section{Author details}

${ }^{1}$ Vector Borne Diseases Control Program, Ministry of Health and Sports, Naypyitaw, Myanmar. ${ }^{2}$ International Union Against Tuberculosis and Lung Disease, The Union South-East Asia Regional Office, New Delhi, India. ${ }^{3}$ Department of Medical Research, Ministry of Health and Sports, Yangon, Myanmar. ${ }^{4}$ Yangon Regional Public Health Department, Department of Public Health, Ministry of Health and Sports, Yangon, Myanmar.

Received: 19 December 2017 Accepted: 22 March 2018

Published online: 16 April 2018

\section{References}

1. World Health Organization. Global Programme to eliminate lymphatic Filariasis: a manual for National Elimination Programmes. 2011.

2. World Health Organization Weekly epidemiological record. World heal organ. 2015

3. Annual Report 2012. Vector Borne Control Programme. Ministry of Health and Sports.

4. Ramzy RMR, El Setouhy M, Helmy H, Ahmed ES, Abd Elaziz KM, Farid HA, et al. Effect of yearly mass drug administration with diethylcarbamazine and albendazole on bancroftian filariasis in Egypt: a comprehensive assessment. Lancet. 2006;367:992-9.

5. Weil GJ, Kastens W, Susapu M, Laney SJ, Williams SA, King CL, et al. The impact of repeated rounds of mass drug administration with diethylcarbamazine plus albendazole on bancroftian filariasis in Papua New Guinea. PLoS Negl Trop Dis. 2008;2:e344.

6. Mitjà O, Paru R, Hays R, Griffin L, Laban N, Samson M, et al. The impact of a filariasis control program on Lihir Island, Papua New Guinea. PLoS Negl Trop Dis. 2011;5:e1286.

7. Liang JL, King JD, Ichimori K, Handzel T, Pa'au M, Lammie PJ. Impact of five annual rounds of mass drug administration with diethylcarbamazine and albendazole on Wuchereria bancrofti infection in American Samoa. Am J Trop Med Hyg. 2008;78:924-8. 
8. Joseph H, Maiava F, Naseri T, Silva U, Lammie P, Melrose W. Epidemiological assessment of continuing transmission of lymphatic filariasis in Samoa. Ann Trop Med Parasitol. 2011;105:567-78.

9. Ramaiah KD, Vanamail P, Yuvaraj J, Das PK. Effect of annual mass administration of diethylcarbamazine and albendazole on bancroftian filariasis in five villages in south India. Trans R Soc Trop Med Hyg. 2011; 105:431-7.

10. Rao RU, Nagodavithana KC, Samarasekera SD, Wijegunawardana AD, Premakumara WDY, Perera SN, et al. A comprehensive assessment of lymphatic filariasis in Sri Lanka six years after cessation of mass drug administration. PLoS Negl Trop Dis. 2014;8:e3281.

11. Toothong T, Tipayamongkholgul M, Suwannapong N, Suvannadabba S. Evaluation of mass drug administration in the program to control imported lymphatic filariasis in Thailand. BMC Public Health. 2015;15:975.

12. Simonsen PE, Derua YA, Kisinza WN, Magesa SM, Malecela MN, Pedersen EM. Lymphatic filariasis control in Tanzania: effect of six rounds of mass drug administration with ivermectin and albendazole on infection and transmission. BMC Infect Dis. 2013;13:335.

13. Richards FO, Eigege A, Miri ES, Kal A, Umaru J, Pam D, et al. Epidemiological and entomological evaluations after six years or more of mass drug administration for lymphatic filariasis elimination in Nigeria. PLoS Negl Trop Dis. 2011:5:e1346.

14. Dickson BFR, Graves PM, McBride WJ. Lymphatic filariasis in mainland Southeast Asia: a systematic review and meta-analysis of prevalence and disease burden. Trop Med Infect Dis. 2017;2(3):32.

15. Nuchprayoon S, Sanprasert V, Porksakorn C, Nuchprayoon I. Prevalence of bancroftian filariasis on the Thai-Myanmar border. Asian Pacific J allergy Immunol. 2003;21:179-88.

16. Satimai W, Jiraamonnimit C, Thammapalo S, Choochote W, Luenee P, Boitano JJ, et al. The impact of a national program to eliminate lymphatic filariasis in selected Myanmar immigrant communities in Bangkok and Ranong Province, Thailand. Southeast Asian J Trop Med Public Health. 2011; 42:1054-64.

17. Bhumiratana A, Koyadun S, Srisuphanunt M, Satitvipawee $P$, Limpairojn $N$, Gaewchaiyo G. Border and imported bancroftian filariases: baseline seroprevalence in sentinel populations exposed to infections with Wuchereria bancrofti and concomitant HIV at the start of diethylcarbamazine mass treatment in Thailand. Southeast Asian J Trop Med Public Health. 2005:36:390-407.

18. Myanmar Information Management Unit. The 2014 Myanmar Population and Housing Census. The Union Report. 2015

19. Ramaiah KD, Vanamail P. Surveillance of lymphatic filariasis after stopping ten years of mass drug administration in rural communities in south India. Trans R Soc Trop Med Hyg. 2013;107:293-300.

20. Babu BV, Babu GR. Coverage of, and compliance with, mass drug administration under the programme to eliminate lymphatic filariasis in India: a systematic review. Trans R Soc Trop Med Hyg. 2014;108:538-49.

21. Shuford KV, Turner HC, Anderson RM. Compliance with anthelmintic treatment in the neglected tropical diseases control programmes: a systematic review. Parasit Vectors. 2016;9:29

22. Richards FO, Eigege A, Miri ES, Kal A, Umaru J, Pam D, et al. Epidemiological and entomological evaluations after six years or more of mass drug administration for lymphatic filariasis elimination in Nigeria. Gyapong JO, editor. PLoS Negl Trop Dis 2011;5:e1346.

23. Addiss DG, Brady MA. Morbidity management in the global programme to eliminate lymphatic filariasis: a review of the scientific literature. Filaria J. 2007;6:2.

\section{Submit your next manuscript to BioMed Central and we will help you at every step:}

- We accept pre-submission inquiries

- Our selector tool helps you to find the most relevant journal

- We provide round the clock customer support

- Convenient online submission

- Thorough peer review

- Inclusion in PubMed and all major indexing services

- Maximum visibility for your research

Submit your manuscript at www.biomedcentral.com/submit 